\title{
Pituitary non-functioning macroadenomas: If and when to recommend surgery
}

\author{
Mara Carsote ${ }^{1,2}$, Ana Valea ${ }^{3,4}$, Mihai Cristian Dumitrascu, ${ }^{2,5}$, \\ Simona Elena Albu2,5, Florica Sandru2,6

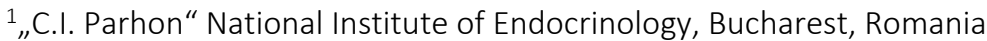 \\ ${ }^{2}$ "Carol Davila" University of Medicine and Pharmacy, Bucharest, Romania \\ ${ }^{3}$ Clinical County Hospital, Cluj-Napoca, Romania \\ 4 „Iuliu Hatieganu“ University of Medicine and Pharmacy, Cluj-Napoca, Romania \\ ${ }^{5}$ Emergency University Hospital, Bucharest, Romania \\ ${ }^{6}$ Elias Emergency University Hospital, Bucharest, Romania
}

\begin{abstract}
Pituitary non-functioning adenomas may be detected based on pituitary insufficiency, eye field complications or headache, etc, so called pituitary mass syndrome.

We introduce a series of three cases of non-functioning pituitary macroadenoma with a different management based on local anatomy of the tumour and complications, as well as the tumour speed of growth.

Non-functioning macroadenoma, even rare, require lifetime follow-up and a rigorous multidisciplinary decision of intervention.
\end{abstract}

Keywords: pituitary adenoma, hypophysectomy, visual field

\section{INTRODUCTION}

Pituitary non-functioning adenomas may be detected based on pituitary insufficiency, hyperprolactiemia, visual field complications or headache, etc, so called pituitary mass syndrome $(1,2,3)$. Typically pituitary incidentaloma have less than $1 \mathrm{~cm}$ diameter and they have a prevalence of $10 \%$ in previously unselected cases $(4,5,6)$. The most frequent secretor pattern of a pituitary adenoma is non-secretor while the most secretion, if any, is of prolactin $(3,7,8)$. Somatotropinoma and corticotropinoma are rarer and typically this types of tumour is associated with a specific phenotype, independent of pituitary mass syndrome $(9,10)$. The non-functioning pituitary macro-adenoma are rarer than microadenomas and they may be accidentally detected or based on local complications (11).

\section{AIM}

We introduce a series of three cases of non-functioning pituitary macroadenomas with a different management based on local anatomy of the tumour and complications, as well as the tumour speed of growth.

\section{MATERIAL AND METHOD}

This is a three cases report. The imaging and endocrine data of the patients are introduced and discussed.

\section{CASE REPORTS}

\section{Patient 1}

This is a 40 years old non-smoker male known with non-secretor pituitary adenoma since the last 5 years. At the beginning of the diagnosis, the maximum diameter was of $1.5 \mathrm{~cm}$ and the tumour was detected because he presented an episode of headache and blurted vision which was spontaneously remitted at that time. The endocrine investigations at that moment showed a negative secretor tumour. The recommendation was to follow-up the tumour every 6 months but the subject delayed the assess- 
ments. Currently the tumour has the largest diameters of 2.7 by $2.5 \mathrm{~cm}$ with intra- and supra-sellar extension (Figure 1). Also multiple areas of small necrosis and calcifications are detected at the level of tumour. The hormonal panel is negative for pituitary insufficiency or hyper-secretion. No eye field anomaly is found. Selective hypophysectomy is performed because of the tumour rate of growth. No endocrine or eye complications are registered immediately after surgery. The pathological report confirms a pituitary adenoma. A remnant of $1.3 \mathrm{~cm}$ is detected at first magnetic resonance imaging which was performed 3 months after selective hypophysectomy.

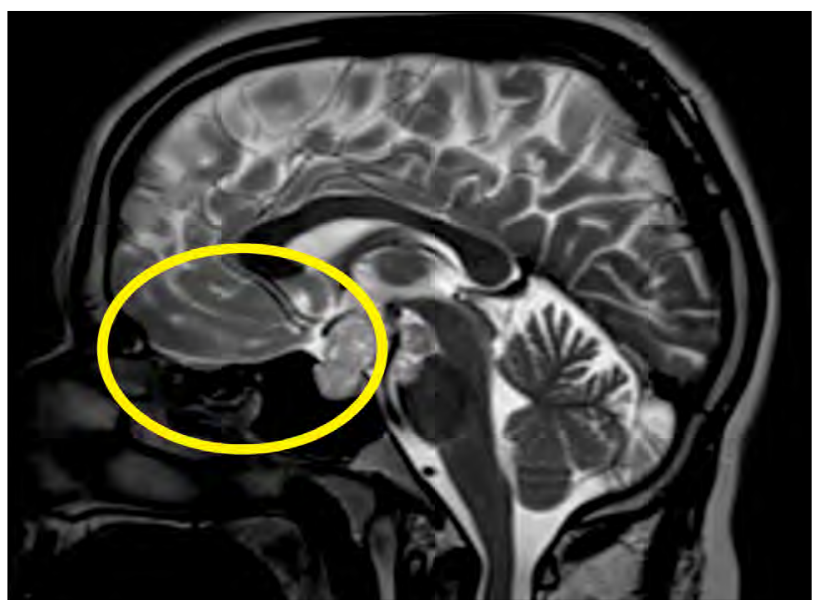

FIGURE 1. Pituitary non-functioning macroadenoma: magnetic resonance imagery aspect on an adult male. The maximum diameters are 2.7 by $2.5 \mathrm{~cm}$. The patient does not associate any endocrine anomalies of the pituitary gland

\section{Patient 2}

This is a 36-year old non-smoker male who recently developed optic chiasm syndrome with rapid

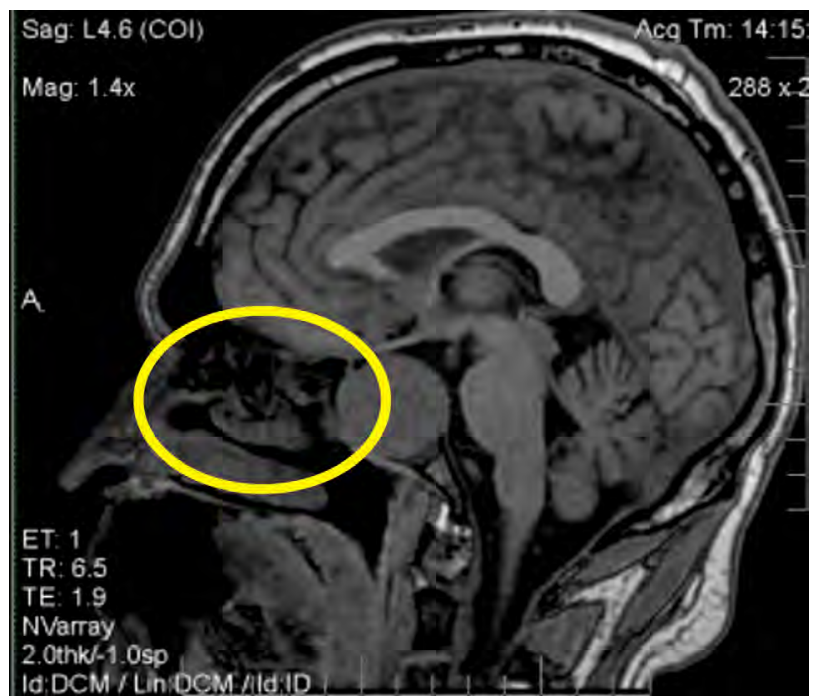

FIGURE 2. Pituitary non-functioning macroadenoma: magnetic resonance imagery aspect on a 36-year old male. The largest diameters are 3.8 by $3.1 \mathrm{~cm}$ evolution. The imaging techniques identified a pituitary macroadenoma of 3.8 by $3.1 \mathrm{~cm}$ with bilateral asymmetrical extension at the level of cavernous sinus (Figure 2). The endocrine assays are normal. He has a selective hypophysectomy done with a partial remission of the optic chiasm syndrome and relapse one year after surgery with indication of re-intervention.

\section{Patient 3}

This is a 52-year old non-smoker female known with a pituitary macroadenoma with negative secretor profile since last 5 years. She had approximately one episode of mild headache per week with amelioration under usual analgesics. The initial diameter was of $1.5 \mathrm{~cm}$ and the tumour displayed a slow rate of growth without compression effects except for a potential connection with mild episodes of headache (one every one to two weeks) which continued with the same pattern (Figure 3). The decision to delay surgery was done and the patient was offered cabergoline up to $2 \mathrm{mg}$ per week to potential shrinkage effects. Close follow-up is necessary.

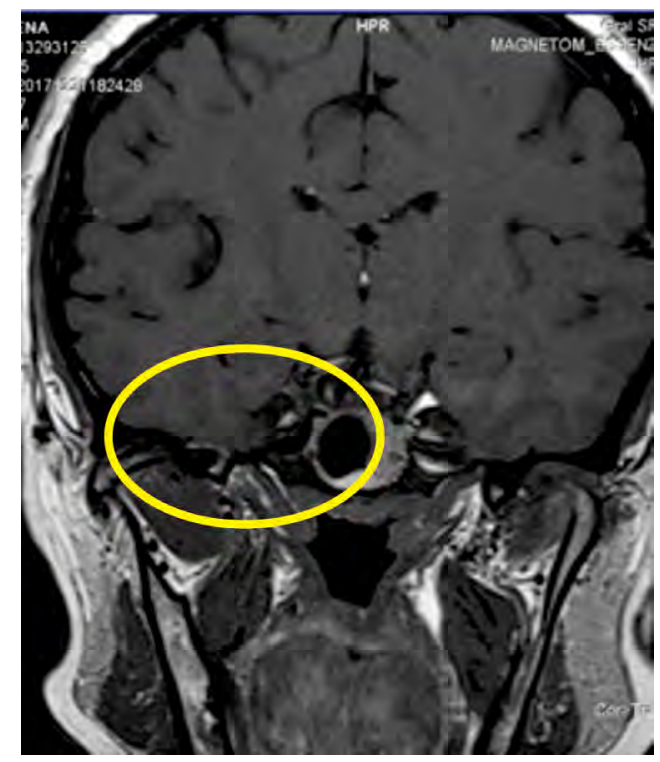

FIGURE 3. Pituitary non-functioning macroadenoma: magnetic resonance imagery aspect on a menopausal female without mass effect

\section{DISCUSSION}

The following aspects are mentioned regarding the presented cases.

\section{Large macroadenomas on young adult males}

The lack of hypogonadism or other endocrine anomalies like secondary hypothyroidism, adrenal 
insufficiency as well as normal ingesta/excreta profile delay the diagnosis of a large pituitary mass (12). In both cases the non-endocrine complications of the tumours as eye field involvement or intense headache episode were suggestive for the mass effect (12). The required surgery in these cases has a relatively low rate of success depending of tumour features and neurosurgeon's experience (13). Re-surgery selective or not, or even trans-frontal approach must be taken into consideration in case of post-operatory persistent disease $(14,15)$. Radiotherapy may stop tumour growth but it is better to be delayed in young patients because of the risk of central hypogonadism (16). The index of proliferation value $\mathrm{Ki} 67$ was of $2 \%$ in the first case and this might explain the relative high rate of growth which is rather unusual for a typical pituitary tumour.

\section{Cabergoline for non-functioning pituitary macroadenomas}

The third case is actually detected as an incidentaloma and thus probably the slow evolution. The adjuvant therapy with cabergoline is the only drug that could help up to $25 \%$ of cases, a drug representing the first line therapy for prolactinomas and also it displays a mild effect on controlling the growth hormone excess in acromegaly especially in combinations with somatostatin analogues (17-19).

\section{REFERENCES}

1. Chanson P, Raverot G, Castinetti F, Cortet-Rudelli C, Galland F, Salenave S; French Endocrinology Society non-functioning pituitary adenoma work-group. Management of clinically non-functioning pituitary adenoma. Ann Endocrinol (Paris). 2015 Jul;76(3):239-47.

2. Poiana C, Chirita C, Carsote M, Hortopan D, loachim D, Corneci CM, Stanescu B. Adrenal and Pituitary Incidentalomas in a Case of Cushing's Syndrome. Chirurgia 2013;6(108):886-891.

3. Poiana C, Chirita C, Carsote M, Hortopan D, Goldstein A. Galactocele and prolactinoma - A pathogenic association? Maturitas. 2009; 62(1):98-102.

4. Gheorghisan-Galateanu AA, Carsote M, Valea A. Incidentaloma: From general practice to specific endocrine frame. J Pak Med Assoc. 2017.67(6):917-922.

5. Gheorghiu M, Hortopan D, Dumitrascu A, Caragheorgheopol A, Stefanescu A, Trifanescu R, Niculescu D, Baciu I, Carsote M, Poiana C, Badiu C, Coculescu M. Age-related endocrine tumors: nonfunctioning adrenal tumors as compared to pituitary adenomas. Acta Endocrinologica, 2009; V(3):371-384.

6. Carsote M, Chirita C, Dumitrascu A, Fica S, Poiana C. Pituitary incidentalomas - How often is too often? Journal of Medicine and Life, 2009; 2(1):92-97.

7. Inoshita N, Nishioka H. The 2017 WHO classification of pituitary adenoma: overview and comments. Brain Tumor Pathol. 2018 Apr; 35(2):51-56.

8. Mete O, Lopes MB. Overview of the 2017 WHO Classification of Pituitary Tumors. Endocr Pathol. 2017 Sep; 28(3):228-243.

\section{Optimal strategy of macroadenomas follow-up}

The first male we introduced was not assessed for 5 years since tumour detection and then the tumour required immediate intervention. Also regarding the menopausal female case neurosurgery was not considered optional yet because of the low speed of growth and non-compressive anatomy of the tumour. The best timing to repeat imaging scans like magnetic resonance imagery or computed tomography for non-functioning pituitary macroadenomas that are not considered candidates for immediate hypophysectomy is still controversial $(20,21)$. If non-secretor microadenomas may be assessed every 1 year and then every 2-3 years, the first assessment for a macroadenoma is needed after 6 months during the first 2-3 years and then yearly if the tumour is stationary $(20,21)$. One study found that a volume growth more than $0.88 \mathrm{~cm} 3 /$ year at magnetic resonance imagery allows the rescan after 2 years while less than mentioned cut off indicates a rescan after 4 years (22). The natural history of pituitary macroadenomas conservatory treated is still a heterogeneous topic (20-22).

\section{CONCLUSION}

Non-functioning macroadenoma, even rare, require lifetime follow-up and a rigorous multidisciplinary decision of intervention.
9. Valea A, Carsote M, Ghervan C, Georgescu C. Glycemic profile in patients with acromegaly treated with somatostatin analogue. Journal of Medicine and Life. 2015; 8(Special Issue):79-83;

10. Valea A, Carsote M, Morar A, Mihalca D, Tarau R, Marcusanu A, Talpasanu A, Chereji A, Georgescu CE. Metabolic approach in patients with active acromegaly: a cross-sectional study of 60 cases. Current Health Sciences Journal. 2015.41(Suppl.1):47-53.

11. Molitch ME. Diagnosis and Treatment of Pituitary Adenomas: A Review. JAMA. 2017 Feb 7; 317(5):516-524.

12. Chanson $P$, Salenave $S$. Diagnosis and treatment of pituitary adenomas. Minerva Endocrinol. 2004 Dec; 29(4):241-75.

13. Harary M, DiRisio AC, Dawood HY, Kim J, Lamba N, Cho CH, Smith TR, Zaidi HA, Laws ER. Endocrine function and gland volume after endoscopic transsphenoidal surgery for nonfunctional pituitary macroadenomas. J Neurosurg. 2018 Nov 1:1-10.

14. Valea A, Turturea R, Botezan O, Moldovan C, Carsote M. Supraorbital craniotomy approach in endocrine-inactive pituitaryadenomas. Journal of Surgical Sciences. 2018; 5(4):233-236.

15. Carsote M, Albu SE, Ghemigian A, Georgescu C, Valea A. Surgical approach in pituitary tumours: the role of endocrine profile. Journal of Surgical Sciences. 2015; 2(4):176-182.

16. Jahangiri A, Wagner JR, Han SW, Tran MT, Miller LM, Chen R, Tom MW, Ostling LR, Kunwar S, Blevins L, Aghi MK. Improved versus worsened endocrine function after transsphenoidal surgery for nonfunctional pituitary adenomas: rate, time course, and radiological analysis. J Neurosurg. 2016 Mar; 124(3):589-95. 
17. Greenman Y, Cooper O, Yaish I, Robenshtok E, Sagiv N, JonasKimchi T, Yuan X, Gertych A, Shimon I, Ram Z, Melmed S, Stern N. Treatment of clinically nonfunctioning pituitary adenomas with dopamine agonists. Eur J Endocrinol. 2016 Jul; 175(1):63-72.

18. Valea A, Carsote M, Ghervan C, Georgescu C. Glycemic profile in patients with acromegaly treated with somatostatin analogue. Journal of Medicine and Life. 2015; 8(Special Issue):79-83.

19. Valea A, Ghervan C, Carsote M, Morar A, lacob I, Tomesc F, Po DD, Georgescu C. Effects of combination therapy: somatostatin analogues and dopamine agonists on GH and IGF1 levels in acromegaly. Clujul Medical. 2015; 88(3):310-313.

20. Lenders N, Ikeuchi S, Russell AW, Ho KK, Prins JB, Inder WJ. Longitudinal evaluation of the natural history of conservatively managed nonfunctioning pituitary adenomas. Clin Endocrinol (Oxf). 2016 Feb; 84(2):222-228.

21. Fernández-Balsells MM, Murad MH, Barwise A, Gallegos-Orozco JF, Paul A, Lane MA, Lampropulos JF, Natividad I, Perestelo-Pérez L, Ponce de León-Lovatón PG, Erwin PJ, Carey J, Montori VM. Natural history of nonfunctioning pituitary adenomas and incidentalomas: A systematic review and metaanalysis. J Clin Endocrinol Metab. 2011 Apr; 96(4):905-12.

22. Kim JH, Dho YS, Kim YH, Lee JH, Lee JH, Hong AR, Shin CS. Developing an optimal follow-up strategy based on the natural history of nonfunctioning pituitary adenomas. J Neurosurg. 2018 Sep 14; 131(2):500-506. 